\title{
UTILIZAÇÃO DA TERMOGRAFIA INFRAVERMELHA COMO FERRAMENTA AUXILIAR NA ANÁLISE DE DURABILIDADE DE ALVENARIAS
}

\author{
VASCONCELOS, GUSTAVO \\ Discente de engenharia civil \\ Universidade de Pernambuco \\ Pernambuco; Brasil \\ gtv@ poli.br
}

\author{
SOBRINHO, CARLOS \\ Docente POLI/Universidade de Pernambuco \\ Universidade de Pernambuco \\ Pernambuco; Brasil \\ carlos@itep.br
}

\author{
PÓVOAS, YÊDA \\ Docente POLI/Universidade de Pernambuco \\ Universidade de Pernambuco \\ Pernambuco; Brasil \\ yeda.povoas@gmail.com
}

\author{
RAMOS, NUNO \\ Docente FEUP/Universidade do Porto \\ Universidade do Porto \\ Porto; Portugal \\ nuno.ramos@fe.up.pt
}

\section{RESUMO}

A norma de desempenho de edificações habitacionais NBR 15575 tem como objetivo de estabelecer requisitos que garantam que as edificações atendam as necessidades dos usuários seja quanto à habitabilidade como também a duração da qualidade. Entre os componentes avaliados, as alvenarias de vedação internas e externas apesar de não terem função estrutural precisam atender outras diversas exigencias, por exemplo, a durabilidade e estanqueidade. $\mathrm{O}$ ensaio sugerido na norma de desempenho é o ensaio de choque térmico e analisa deflecções e analises visuais das patologias que possam surgir em 10 ciclos de aquecimento e resfriamento. Com o objetivo de ampliar a análise realizada, nesse estudo foi utilizado a termografia infravermelha, uma técnica não destrutiva e comprovadamente eficiente na identificação de manifestações patológicas, para identificar e acompanhar a progressão de possíveis infiltrações na alvenaria de blocos de gesso hidrofugado (resistentes à água). Avaliando o primeiro ciclo, já foi possível comprovar a eficiencia da termografia na identificação dessa manifestação patológica e acompanhar a evolução da ação da água na alvenaria conforme o decorrer do ensaio, confirmando essa técnica como uma ferramenta de grande utilidade nas análises de durabilidade das alvenarias.

Palavras-chave: termografia infravermelha, durabilidade, alvenaria, infiltrações, blocos de gesso hidrofugado.

\section{ABSTRACT}

The performance standard of housing buildings NBR 15575 aims to establish requirements that ensure that buildings meet user's needs for both habitability and quality duration. Among the evaluated components, the internal and external sealing masonry, although not having a structural function, must meet several other requirements, such as durability and tightness. The test suggested in the performance standard is the thermal shock test and analyzes deflections and visual analyzes of pathologies that may arise in 10 heating and cooling cycles. In order to broaden the analysis performed, this study used infrared thermography, a non-destructive technique that has been shown to be efficient in identifying pathological manifestations, to identify and monitor the progression of possible infiltration into the masonry of waterresistant plaster blocks (water resistant). Evaluating the first cycle, it was already possible to prove the efficiency of thermography in the identification of this pathological manifestation and to follow the evolution of the water action in the masonry as the test proceeds, confirming this technique as a very useful tool in the durability analyzes of the masonry.

Keywords: infrared thermography, durability, masonry, infiltrations, water repellent plasterblocks.

\section{INTRODUÇÃO}

A norma de desempenho NBR 15575 (ABNT, 2013) tem o objetivo de estabelecer requisitos minimos para assegurar o bom funcionamento do processo construtivo aos futuros usuários. Dentre os requisitos, está a durabilidade das habitações, que possui uma importância tanto econômica, com um menor custo de manutenção e operação, quanto 
ambiental, no maior tempo de vida útil e consequentemente, maior tempo para ser reposto (RESENDE, 2018). Para o estudo de durabilidade de um sistema construtivo é preciso considerar agentes que afetam o conjunto e não os componentes isoladamente. Apesar de se haver muitos estudos relacionados aos materiais e componente, a dificuldade em se realizar estudos considerando o conjunto construtivo muitas vezes está na dificuldade de interpretar os resultados obtidos nos ensaios (OLIVEIRA, FONTENELLE \& MITIDIERI, 2014). Isso reforça a indespensabilidade de revisões das técnicas utilizadas, visando acompanhar o desenvolvimento tecnológico e as exigências do mercado (BENTO et al, 2016).

Produtos baratos no médio e curto prazo podem originar altos custos de manutenção, produção e de gestão de resíduos demasiados (BRIBÍAN et al, 2016). Por isso que a durabilidade dos materiais é fundamental para garantir a vida útil dos sistemas construtivos. Existem normas que regulamentam a utilização desses produtos como a NBR 16494 (ABNT, 2017) e a NBR 16495 (ABNT, 2017) que se refere a blocos de gesso para vedação vertical, porém, com um insuficiente material técnico acerca da utilização de gesso na construção civil ainda é dificil ter a aprovação da classe consumidora, apesar do constante crescimento do mercado (BISPO \& FRÓIS, 2017) e apesar da indústria da construção civil já vir utilizando-os em vedações verticais internas e externas, especialmente no nordeste brasileiro (SANTOS, RAMOS \& DELGADO, 2018). A grande utilização dos blocos de gesso se dá principalmente nas vantagens quando comparado com a alvenaria tradicional com blocos cerâmicos como o aumento da produtividade e redução de resíduos e a redução do peso da estrutura e menor consumo de concreto nas fundações e superestrutura, (PIRES SOBRINHO et al, 2011). Porém, utilizar alvenaria de gesso em fachadas pode resultar em uma baixa durabilidade em locais com condições climáticas desfavoráveis, alta precipitação e baixa exposição ao sol, (SANTOS, RAMOS \& DELGADO, 2018).

A umidade é um problema recorrente em fachadas de edifícios e no interior de residências e pode estar relacionada desde o aparecimento de manchas até uma desagregação do material (PEREIRA, DE BRITO \& SILVESTRE, 2018). Um método não destrutivo, fácil e eficaz de avaliar o surgimento dessas manifestações patológicas é a utilização de termografia infravermelha, especialmente em fachadas. Os possíveis defeitos na estrutura podem ser identificados por uma diferença de temperatura, representados em diferentes colorações nos termogramas (SILVA, VIÉGAS \& PÓVOAS, 2016) e isso pode ser realçado quando na presença de umidade, influenciando diretamente na relação entre a temperatura e a qualidade das imagens obtidas (DOS SANTOS et al, 2018).

O presente estudo utilizou a termografia infravermelha para acompanhar o ensaio de ação de calor e choque térmico, proposto pela NBR 15575 (ABNT, 2013) para a análise de durabilidade, com o objetivo de levantar informações que contribuam para uma análise ainda mais completa, tanto do método aplicado quanto da capacidade da termografia em identificar possiveis manifestações patológicas como as infiltrações.

\section{MATERIAIS E MÉTODOS}

Para realização desta pesquisa foi realizada a caracterização dos blocos de gesso para sua utiliazação nos sistemas de vedações verticais conforme os requisitos estabelecidos pela NBR 16494 (ABNT, 2017) e os métodos de ensaios propostos pela NBR 16495 (ABNT, 2017).

Nesse estudo utilizou-se da termografia infravermelha para acompanhar um ensaio de choque térmico em alvenaria de bloco de gesso. O ensaio foi realizado de acordo com o anexo E da norma de desempenho NBR 15575-4 (ABNT, 2013) que consiste em 10 ciclos de exposição ao calor seguido pelo resfriamento por jatos de água, sendo avaliado no presente estudo apenas o primeiro ciclo.

\subsection{Materiais}

Foi construida uma alvenaria em pórtico em perfil de aço com dimensões de 1,60m x 2,35m com blocos de gesso compactos de dimensões $666 \mathrm{~cm}$ × $500 \mathrm{~cm}$ x $10 \mathrm{~cm}$ do tipo standard. O gesso cola utilizado foi do tipo hidrófugo comercialmente utilizado e a relação água/gesso foi a recomendada pelo fabricante.

\subsection{Métodos}

\subsubsection{Caracterização dos blocos}

Os blocos de gesso foram caracterizados quanto à densidade, à espessura, ao comprimento, à altura, à resistência à tração na flexão e à capacidade de absorção de água por imersão total conforme NBR 16495 (ABNT, 2017). 


\subsubsection{Ensaio de choque térmico}

Para realização do ensaio de choque térmico, seguiu-se o anexo E da NBR 15575-4 (ABNT, 2013) com a utilização de um painel eletrônico de resistências de $24 \mathrm{~kW}$ com dimensões de $1,19 \mathrm{~m}$ x 2,39 m, posicionado na face externa da alvenaria (Figura 1a). Cinco termopares foram inseridos na superfície da alvenaria que foi exposta ao calor, com o objetivo de controlar a temperatura da parede como requisitado na norma.

Ao ligar o painel, houve o aumento gradativo da temperatura até a estabilização aos $80^{\circ} \mathrm{C}$. Após a estabilização, manteve-se a alvenaria exposta durante 60 minutos a esta temperatura (Figura 1b) e, posteriormente à supressão do calor, a superfície foi resfriada com jatos d'água até a temperatura da superfície da face externa se estabilizar com a temperatura ambiente. O sistema de resfriamento da face externa foi composto por um cano na parte superior do pórtico inserido em uma calha metálica para distribuir o resfriamento uniformemente na alvenaria.

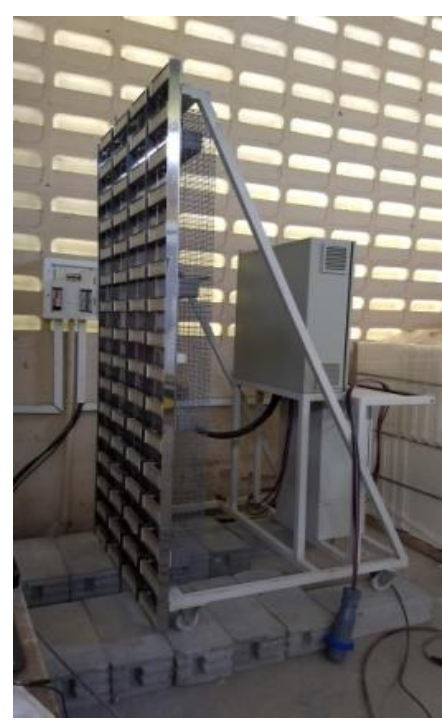

(a)

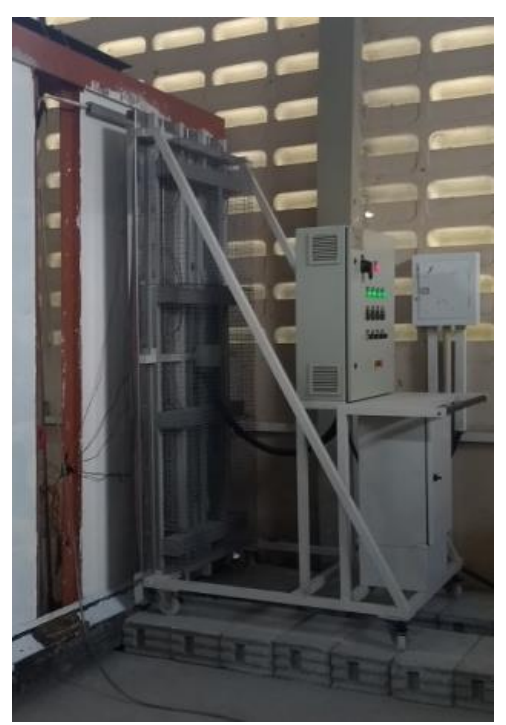

(b)

Figura 1 - (a) Painel eletrônico posicionado em frente a alvenaria, (b) equipamento posicionado de frente a alvenaria durante ensaio.

\subsubsection{Termografia infravermelha}

A análise com termografia infravermelha foi realizada com uma câmera FLIR E60 (Figura 2) de resolução 320 x 240 pixels e de precisão $\pm 2^{\circ} \mathrm{C}$ ou $\pm 2 \%$ de leitura, a qual pode atuar em uma faixa de temperatura de $-20^{\circ} \mathrm{C}$ a $650^{\circ} \mathrm{C}$. Os termogramas foram capturados a uma distância de aproximadamente 5 metros da face oposta à incidência de calor (interna) e a 4 metros na face externa, a uma altura de 1,50m e perpendicularmente a alvenaria para haver uma mínima influência da angulação como mostrado no estudo realizado por da Silva Vieira et al (2018). Os parâmetros considerados foram 0,91 para emissividade do gesso (método da fita preta) e $29^{\circ} \mathrm{C}$ para a temperatura reflectida (considerando igual à temperatura ambiente), como proposto no estudo realizado por Marinoski et al (2010). O software utilizado para tratar os termogramas foi o FLIR Tools, disponibilizado gratuitamente para download e utilização pela mesma empresa fabricante.

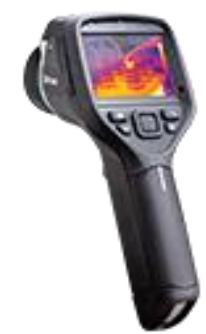

Figura 2 - Câmera termográfica FLIR E60.

Fonte: www.flir.com.br 


\section{RESULTADOS}

\subsection{Caracterização dos blocos}

Os blocos foram classificados como compactos de média densidade, possuindo dimensões entre os limites estabelecidos e, principalmente, por possuir uma boa resistência à tração na flexão de aproximadamente o dobro da exigida na norma de blocos de gesso. A capacidade de absorção é um requisito para blocos hidrofugados (resistentes à água), mas os valores na faixa de $24 \%$ comprovam a capacidade dos blocos standard absorverem água e, desse modo, indicam uma possível fragilidade quanto à durabilidade do material visto que a umidade é um problema para fachadas e alvenarias externas (PEREIRA, DE BRITO \& SILVESTRE, 2018). Tais resultados validam a utilização desses blocos de gesso em alvenarias de vedação vertical.

Tabela 1 - Resultados obtidos e critérios da caracterização dos blocos de gesso standard

\begin{tabular}{|c|c|c|}
\hline PROPRIEDADES & $\begin{array}{l}\text { RESULTADOS } \\
\text { (Valor médio) }\end{array}$ & $\begin{array}{l}\text { CRITÉRIOS DA NBR } 16494 \\
\text { (ABNT, 2017) }\end{array}$ \\
\hline \multirow{3}{*}{ Densidade $\left(\mathrm{Kg} / \mathrm{m}^{3}\right)$} & \multirow{3}{*}{1049,9} & Alta densidade $\geq 1100$ \\
\hline & & $800 \leq$ Média densidade $<1100$ \\
\hline & & $600 \leq$ Baixa densidade $<800$ \\
\hline Dimensões (cm) & $666,7 \times 500,6 \times 100,1$ & $\begin{array}{l}666,0 \pm 3,0 \\
500,0 \pm 2,0 \\
100,0 \pm 0,5\end{array}$ \\
\hline Resistência à tração na flexão (MPa) & 2,90 & $\geq 1,5$ \\
\hline $\begin{array}{c}\text { Absorção de água por imersão total } \\
(\%)\end{array}$ & 24,0 & $\leq 5 \%$ para blocos hidrófugos \\
\hline
\end{tabular}

\subsection{Análise do ensaio de choque térmico com a termografia infravermelha}

$\mathrm{O}$ painel eletrônico foi ligado às $15 \mathrm{~h} 13$ e a temperatura da alvenaria se estabilizou em $80^{\circ} \mathrm{C}$ após 20 minutos. A exposição ao calor manteve-se a essa temperatura até $16 \mathrm{~h} 33$. Nesse período, foi registrada a face interna da alvenaria (lado oposto à incidência do calor) com uma temperatura ambiente de $29^{\circ} \mathrm{C}$, umidade relativa do ar de $51 \%$ e distância de 5 metros. Após a supressão do calor foi registrada a face externa, exposta ao calor, da alvenaria em duas situações: antes e após a ação do resfriamento. Esses termogramas foram tirados a uma distância de aproximadamente 4 metros. Toda esquematização dos termogramas registrados estão dispostos na Tabela 2.

Tabela 2: Esquematização dos termogramas registrados

\begin{tabular}{|c|c|c|}
\hline HORÁRIO & $\begin{array}{l}\text { DESCRIÇÃO } \\
\text { (face interna) }\end{array}$ & $\begin{array}{l}\text { DESCRIÇÃO } \\
\text { (face externa) }\end{array}$ \\
\hline $15 \mathrm{~h} 13$ & \multicolumn{2}{|c|}{ Inicio da exposição ao calor até a temperatura estabilizar em $80^{\circ} \mathrm{C}$. } \\
\hline \multirow{2}{*}{$15 \mathrm{~h} 33$} & \multicolumn{2}{|c|}{ Estabilização em $80^{\circ} \mathrm{C}$ e inicio da contagem da exposição ao calor durante $1 \mathrm{~h}$} \\
\hline & Figura 3a & - \\
\hline \multirow{2}{*}{$16 \mathrm{~h} 03$} & \multicolumn{2}{|c|}{30 min de exposição ao calor à temperatura de $80^{\circ} \mathrm{C}$} \\
\hline & Figura $3 b$ & - \\
\hline \multirow{2}{*}{$16 \mathrm{~h} 33$} & \multicolumn{2}{|c|}{ Fim da exposição ao calor } \\
\hline & Figura 3c & Figura 4 \\
\hline \multirow{2}{*}{$16 \mathrm{~h} 35$} & \multicolumn{2}{|c|}{ Inicio do resfriamento com jatos de água } \\
\hline & - & Figura 5 \\
\hline $16 \mathrm{~h} 46$ & Figura $6 a$ & - \\
\hline $17 \mathrm{~h} 02$ & Figura $6 b$ & - \\
\hline $17 \mathrm{~h} 15$ & Figura $6 \mathrm{c}$ & - \\
\hline \multirow{2}{*}{$17 \mathrm{~h} 43$} & \multicolumn{2}{|c|}{ Fechamento do registro e fim do ensaio } \\
\hline & Figura 6d & - \\
\hline
\end{tabular}




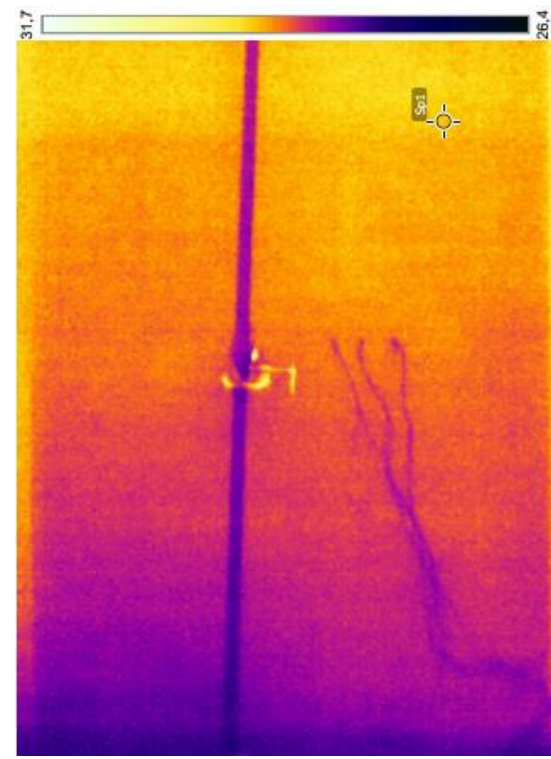

(a)

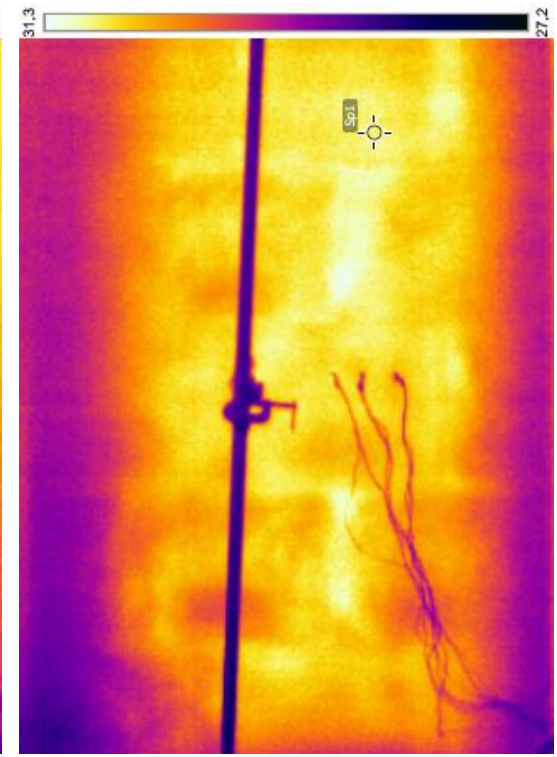

(b)

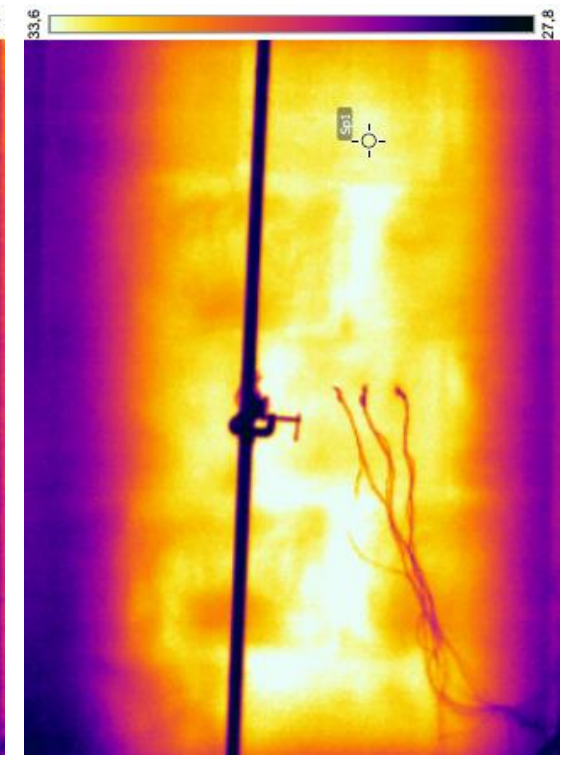

(c)

Figura 3: (a) 15:33h (no momento da estabilização), (c) 16:03h (30 min após estabilização) e (d) 16:33h (antes do desligamento do equipamento).

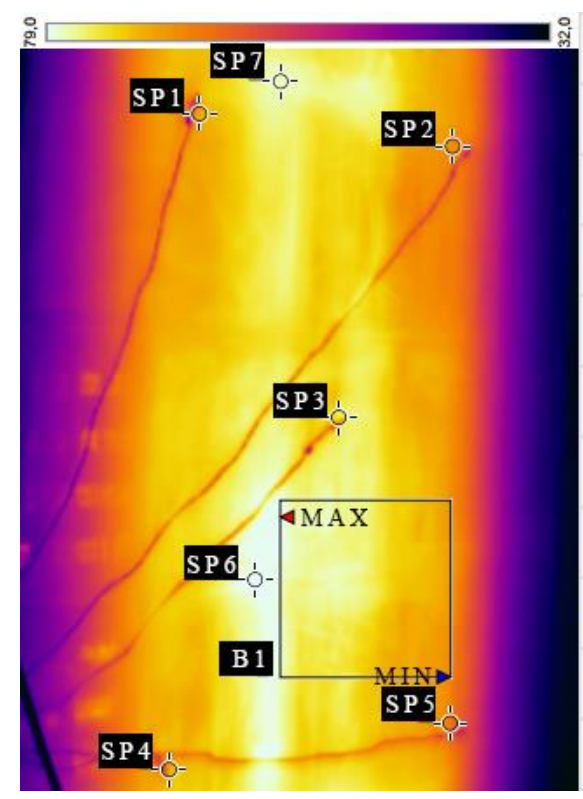

\begin{tabular}{|c|c|}
\hline PONTO & $T\left({ }^{\circ} \mathrm{C}\right)$ \\
\hline SP1 & 70,2 \\
\hline SP2 & 68,3 \\
\hline SP3 & 75,2 \\
\hline SP4 & 70,7 \\
\hline SP5 & 64,7 \\
\hline SP6 & 79,5 \\
\hline SP7 & 77,6 \\
\hline B1 T MÁX & 79,2 \\
\hline B1 T MÍN & 66,1 \\
\hline B1 T MED & 74,0 \\
\hline
\end{tabular}

Figura 4: Face externa da alvenaria após a supressão do calor e afastamento do equipamento

Durante o processo de resfriamento com os jatos de água (Figura 5), acompanhou-se ambas as faces analisando as possíveis manifestações patológicas que surgissem na alvenaria. Apenas com o primeiro ciclo não foi suficiente para causar fissuras na alvenaria, mas após aproximadamente nove minutos foi possível identificar infiltrações em dois pontos (Figura 6a) o que se é esperado devido à suscetibilidade dos blocos standard absorverem água comprovado nos testes de caracterização.

A ocorrência de infiltração foi bastante evidenciada durante o processo de resfriamento nos termogramas, tanto no aumento das manchas escuras (circuladas) das primeiras infiltrações, quanto no aparecimento de outras. 

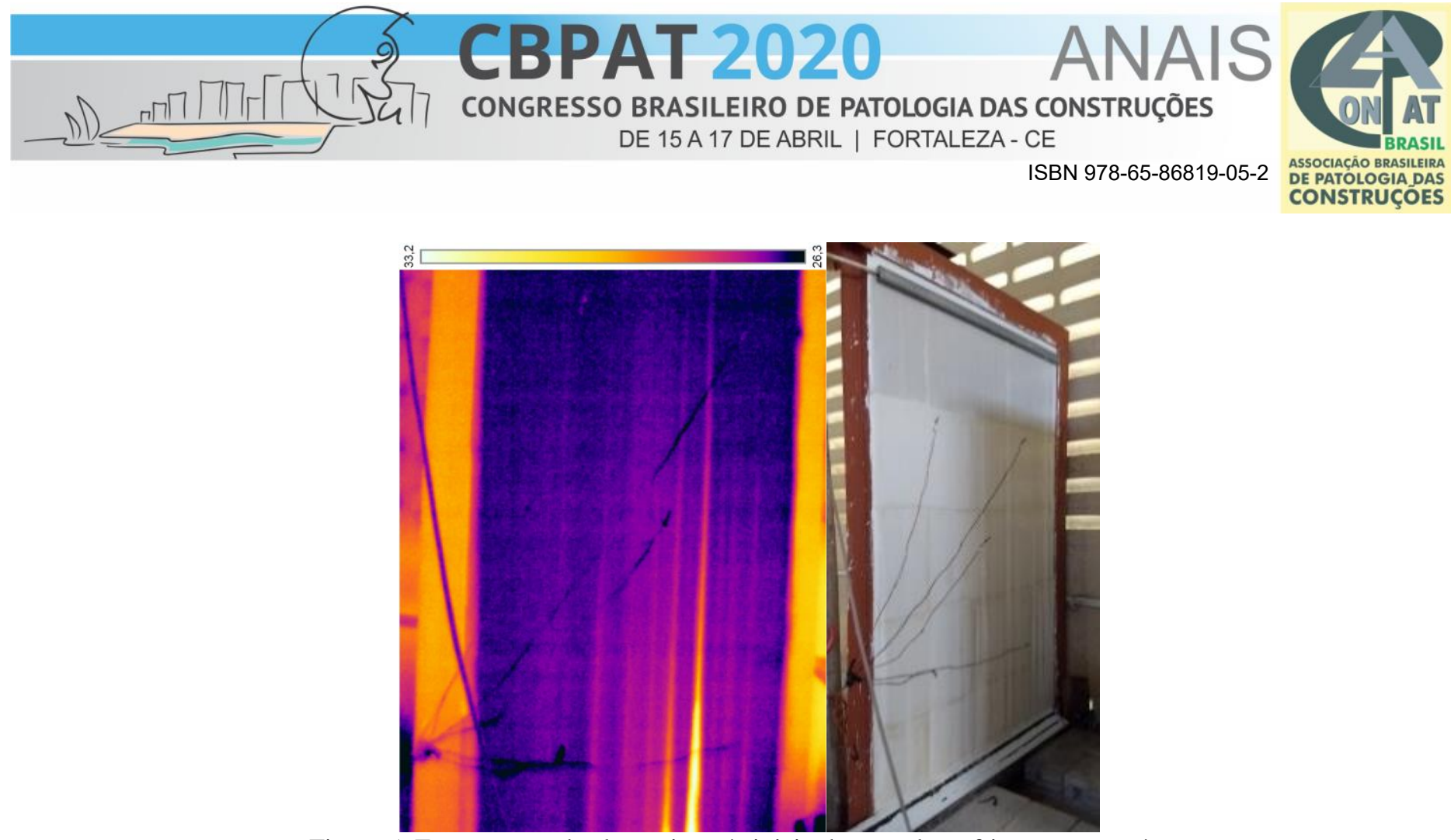

Figura 5: Face externa da alvenaria após inicio da ação de resfriamento com água

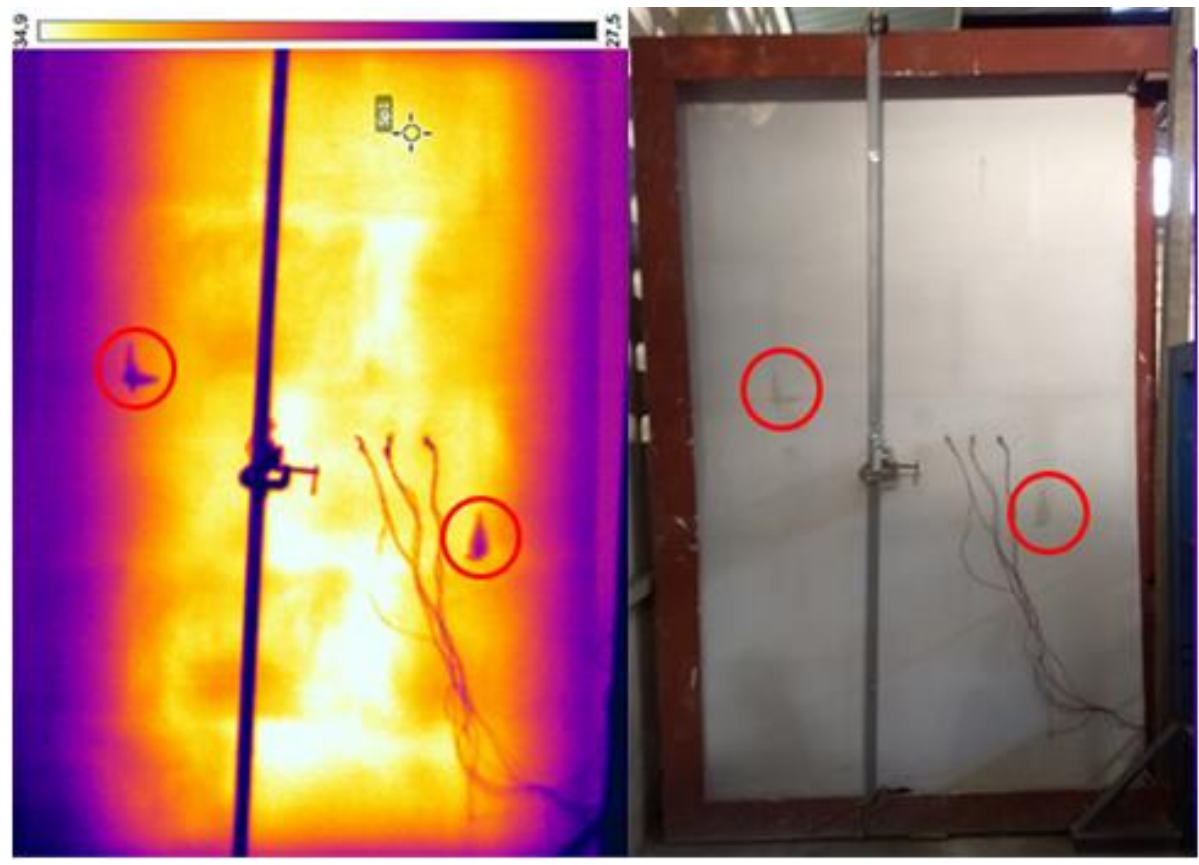

(a) 


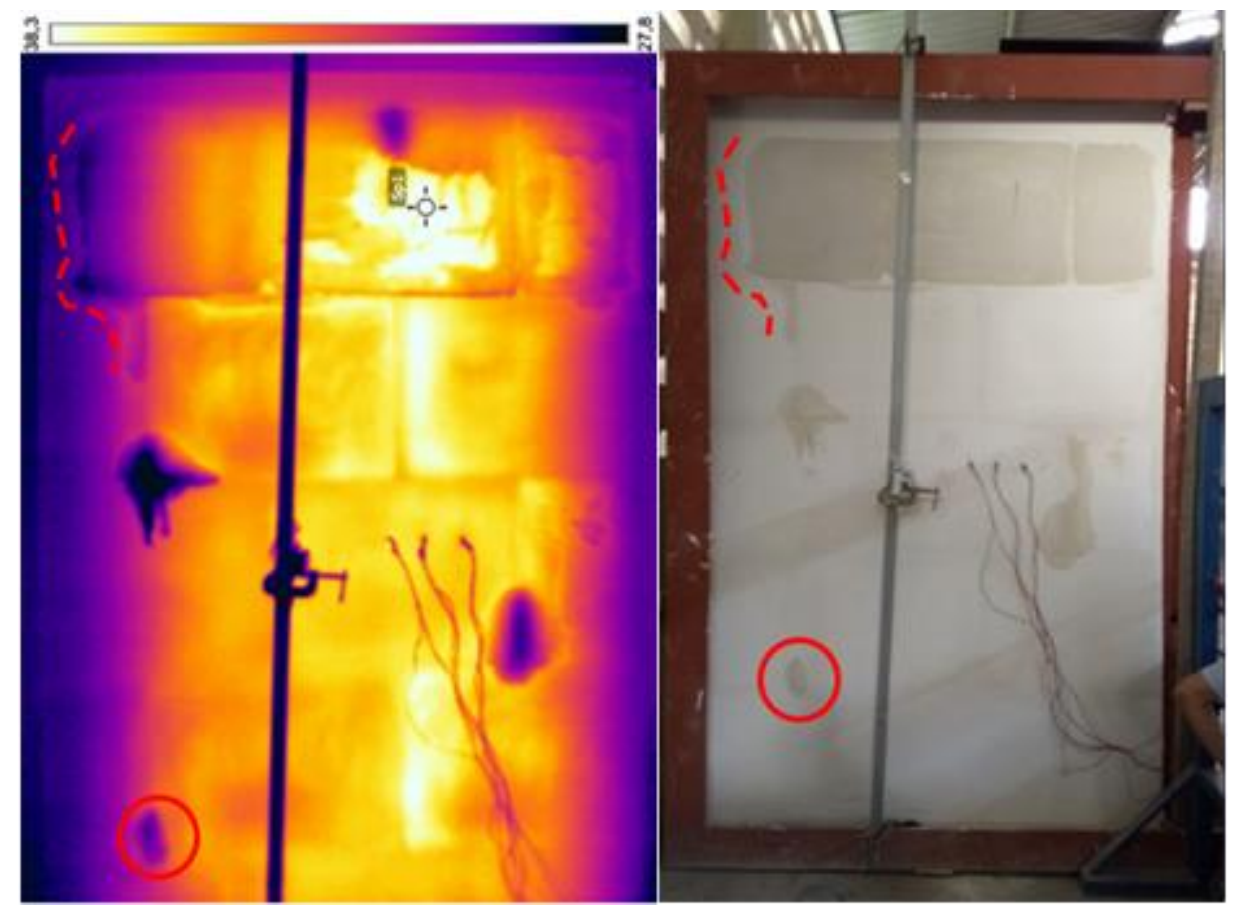

(b)

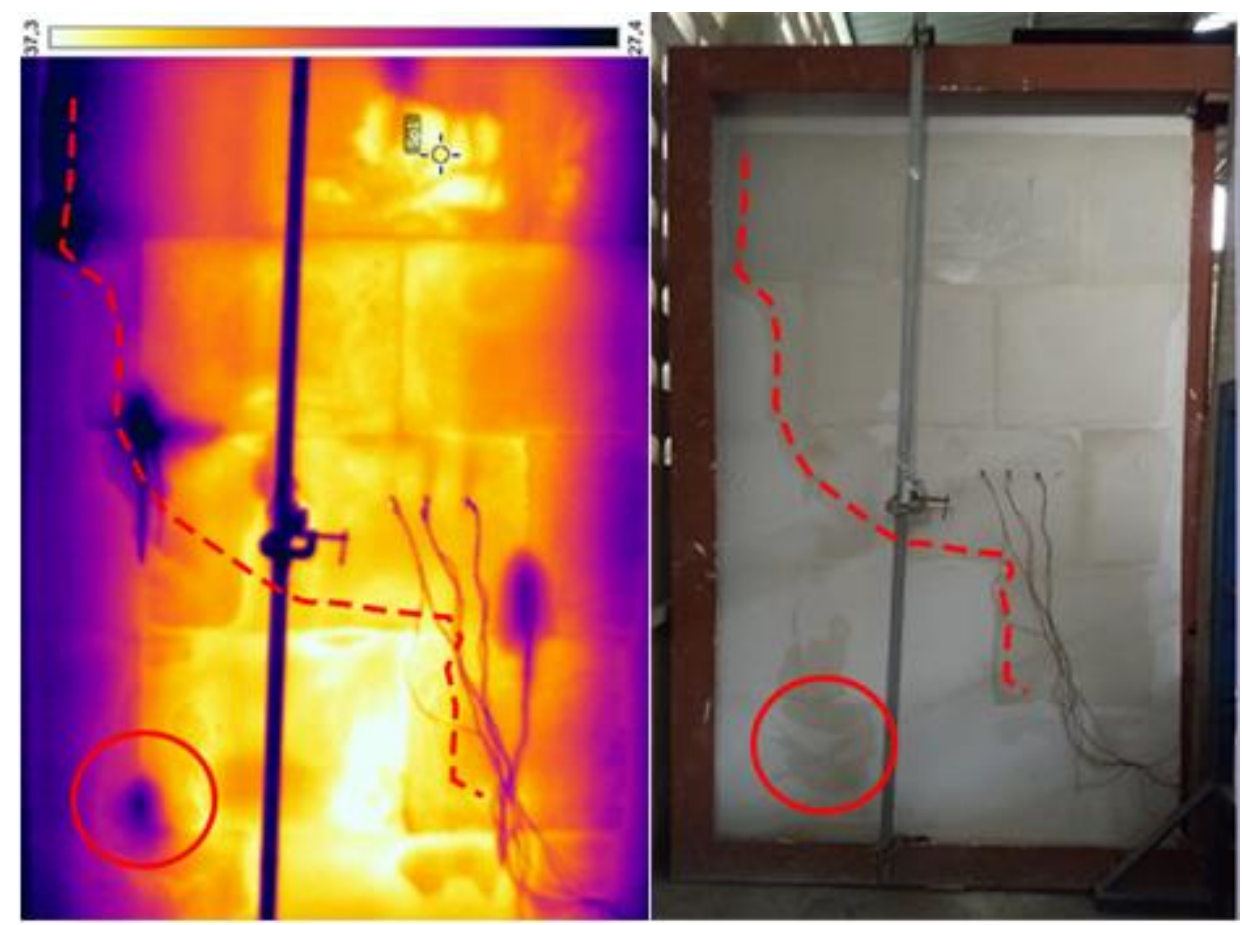

(c) 


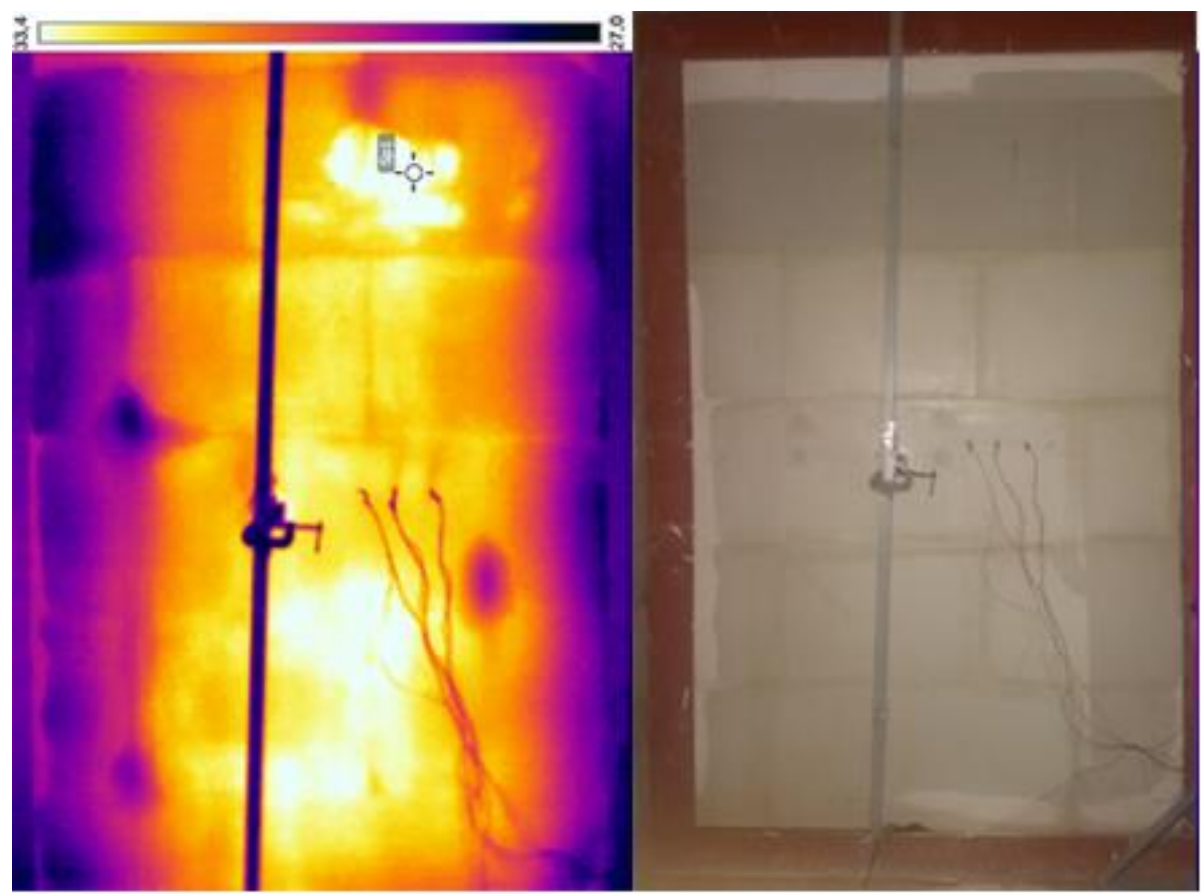

(d)

Figura 6: Face interna da alvenaria após inicio da ação de resfriamento com água nos instantes de (a) 16h46, (b) 17h02, (c) $17 \mathrm{~h} 15$ e (d) $17 \mathrm{~h} 43$.

\section{CONCLUSÕES}

A partir das informações coletadas nesse estudo, pode-se levantar as seguintes conclusões:

Quando ao método do ensaio de choque térmico: Pode-se perceber nos termogramas que o painel eletrônico não conseguiu distribuir de forma uniforme o calor para a alvenaria. Isso ficou evidenciado na Figura 4 onde é notável que há uma concentração do calor no centro da área de exposição. A temperatura dos pontos SP1, SP2, SP4 e SP5 localizados nas extremidades foram os menores, por outro lado os pontos mais centrais apresentaram uma temperatura mais próxima dos $80^{\circ} \mathrm{C}$. O que pode ter sido influenciado, tanto pelo não isolamento das bordas entre o painel e alvenaria, e por esta razão a possibilidade de influência da temperatura ambiente e de correntes de ar, quanto devido ao tamanho da alvenaria $(1,60 \times 2,35 \mathrm{~m})$ comparado ao tamanho da área de exposição $(1,19 \times 2,39 \mathrm{~m})$, que pode ter dissipado o calor. Com isso, a utilização da câmera termográfica durante o ensaio de choque térmico para avaliar a aplicação do método proposto é bastante útil, uma vez que com apenas um termograma pode-se retirar dados de temperatura de qualquer ponto da alvenaria e conferir se a temperatura superficial da mesma está uniforme.

Quanto à indentificação de manifestações patológicas: Apenas um ciclo não foi suficiente para haver fissuras ou outro tipo de degradação na alvenaria de blocos de gesso standard. Porém devido à suscetibilidade desse produto à ação da água, após 9 min já foi possível identificar dois pontos de infiltração. Apesar de que devido à ação da água corrente na alvenaria durante o resfriamento não foi possível fazer leituras da temperatura da face interna da alvenaria com a câmera termográfica, pois a leitura realizada era da temperatura da água e não da superfície da parede, é interessante identificar a formação de novas manchas de umidade e acompanhar o avanço das mesmas na superficie oposta, como também visualizar uma linha de contorno dessa mancha de umidade (Figura $6 \mathrm{~b}$ e $6 \mathrm{c}$ ). O que confirma a eficiência da termografia infravermelha na identificação de manifestações patológicas e mais uma vez a indica como uma boa aliada no estudo sobre a durabilidade das estruturas. 


\section{REFERÊNCIAS}

ASSOCIAÇÃO BRASILEIRA DE NORMAS E TÉCNICAS. NBR 15575: Desempenho de edificações habitacionais. Rio de Janeiro, 2013.

ASSOCIAÇÃO BRASILEIRA DE NORMAS E TÉCNICAS. NBR 15575-4: Edificações habitacionais Desempenho. Parte 4: Requisitos para os sistemas de vedações verticais internas e externas - SVVIE. Rio de Janeiro, 2013.

ASSOCIAÇÃO BRASILEIRA DE NORMAS E TÉCNICAS. NBR 16494: Bloco de gesso para vedação vertical Requisitos. Rio de Janeiro, 2017.

ASSOCIAÇÃO BRASILEIRA DE NORMAS E TÉCNICAS. NBR 16495: Bloco de gesso para vedação vertical Método de ensaio. Rio de Janeiro, 2017.

BENTO, A.; NEVES, D.; PIRES, J.; OLIVEIRA, M.; SILVA, D. A influência da NBR 15575 (2013) na durabilidade e vida útil das edificações residenciais. Seminário de Patologia e Recuperação Estrutural, Recife, Brasil, 2016.

BISPO, V. M. S.; FRÓIS, M. R. A aplicabilidade de gesso no processo de industrialização da construção civil. ETIC Encontro de Iniciação Científica - ISSN 21-76-8498, v. 13, n. 13, 2017.

BRIBIÁN, I. Z.; CAPILLA, A. V.; USÓN, A. A. Life cycle assessment of building materials: Comparative analysis of energy and environmental impacts and evaluation of the eco-efficiency improvement potential. Building and environment, v. 46, n. 5, p. 1133-1140, 2011.

DA SILVA VIEIRA, G., HARTMANN, D. A., ROCHA, A. M. S. C., KIYOTANI, M. S. M. Termografia infravermelha: influência das variações de distância, emissividade e ângulo de observação. Anais do Salão Internacional de Ensino, Pesquisa e Extensão, v. 9, n. 3, 2018.

DOS SANTOS, C. F.; ROCHA, J. H. A.; BATISTA, P. I. B.; TAVARES, Y. V. P. Potencialidade da termografia infravermelha na deteç̧ão de infiltrações em edificações. In: $6^{\text {a }}$ conferência sobre patologia e reabilitação de edifícios, Anais... 2018.

MARINOSKI, D. L.; SOUZA, G. T.; SANGOI, J. M.; LAMBERTS, R. Utilização de imagens em infravermelho para análise térmica de componentes construtivos. In: XIII Encontro Nacional de Tecnologia do Ambiente Construído, Anais... 2010.

OLIVEIRA, L. A.; FONTENELLE, J. H.; MITIDIERI FILHO, C. V. Durabilidade de fachadas: método de ensaio para verificação da resistência à ação de calor e choque térmico. Ambiente Construído, v. 14, n. 4, p. 53-67, 2014.

PEREIRA, C.; DE BRITO, J.; SILVESTRE, J. D. Contribution of humidity to the degradation of façade claddings in current buildings. Engineering Failure Analysis, v. 90, p. 103-115, 2018.

PIRES SOBRINHO, C. W. A.; BEZERRA, N. M.; COSTA, T. C. T.; SILVA, C. B. A. "Divisórias internas de edifícios em alvenaria de blocos de gesso-vantagens técnicas, econômicas e ambientais." Instituto de Tecnologia de Pernambuco (2011).

RESENDE, H. F. Uso de análise numérica no estudo da resistência à ação de calor e choque térmico em painéis de fachada. Construindo, v. 10, n. 1, p. 75-91, 2018.

SANTOS, A., RAMOS, N.M.M., MAIA, J. \& DELGADO, J.M.P.Q. Hygrothermal performance of Brazilian gypsum walls. Journal of Building Physics, p. 1744259118779021, 2018.

SILVA, A. J.; VIÉGAS, D. J. A.; PÓVOAS, Y. V. O uso da termografia infravermelha para deteç̧ão de manifestações patológicas. In: Encontro Nacional de Tecnologia do Ambiente Construído, 16., 2016, São Paulo. Anais... Porto Alegre: ANTAC, 2016. 